\title{
ÁNGEL FERRANT Y LA REFORMA DE LAS ESCUELAS SUPERIORES DE BELLAS ARTES
}

\author{
POR \\ IgNACIO AsEnJo FernÁNDEZ \\ Universidad Complutense de Madrid
}

\begin{abstract}
En plena Guerra Civil, el gobierno de la Segunda República española creó un Consejo Central de Artes Plásticas para reorganizar las enseñanzas artísticas y la Escuela de Arquitectura. El escultor Ángel Ferrant formó parte activa de la Comisión de expertos. El artículo examina el proyecto de reorganización de las Escuelas Superiores de Bellas Artes elaborado por Ferrant.
\end{abstract}

Palabras clave: Ángel Ferrant; Escuelas Superiores de Bellas Artes; Educación artística; Enseñanza general; Barcelona; 1938.

During the Spanish Civil War, the government of the Second Republic created the Central Council for Fine Arts in order to reorganize teaching at schools of Fine Arts and Architecture. The sculptor Ángel Ferrant was an active member of this Commission of experts. This article examines Ferrant's project for the reorganization of Fine Arts schools.

Key words: Ángel Ferrant; Fine Arts schools; Art education; Barcelona; 1938.

Con el fin de reorganizar a fondo todas las cuestiones de la enseñanza artística, el gobierno de la Segunda República española creó a finales de 1937, en plena Guerra Civil, un Consejo Central de Artes Plásticas. Uno de sus objetivos era reformar las Escuelas Superiores de Bellas Artes y la de Arquitectura. Para llevar a cabo dicha reforma se nombró una Comisión de expertos, de la cual formó parte activa como miembro el escultor Ángel Ferrant (1890-1961). Éste fue, además de artista, un excelente docente. Con vocación probada, practicó el magisterio en distintas Escuelas de Artes Aplicadas y Oficios Artísticos -en Madrid, La Coruña y Barcelona- durante cuatro décadas, impulsando eficazmente la enseñanza de la escultura desde su modesta cátedra de modelado. La reforma de la pedagogía artística fue una de sus grandes preocupaciones; en este sentido, se mostró receptivo a las corrientes avanzadas del cambio de siglo. Asimismo, tuvo oportunidad de analizar los procedimientos pedagógicos que se empleaban para la enseñanza del arte en el extranjero. Precisamente, en 1927 Ferrant recibió una pensión de la Junta para Ampliación de Estudios con el fin de estudiar en Viena el régimen y funcionamiento de las instituciones 
artístico-docentes de esa ciudad, principalmente de sus escuelas de artes y oficios, entre las cuales se encontraba la Kunstgewerbeschule.

Muy pronto, Ferrant se mostró contrario a los métodos pedagógicos empleados en su tiempo para la enseñanza y el aprendizaje del arte. En 1931, siendo profesor de la Escuela de Artes y Oficios y Bellas Artes de Barcelona -la Llotja-, redactó un programa sobre la reorganización de la enseñanza artística, dentro de las que llamó Escuelas Federadas de Artes Plásticas del Estado; dicho programa fue discutido ampliamente en su momento. Ferrant lo denominó Diseño de una configuración escolar. El Estado y las artes plásticas, y su contenido se publicó en varias ocasiones en 1932 y 1933. En dicho texto, Ferrant formulaba un plan de estudios y varias propuestas concretas para mejorar la formación de los estudiantes de artes plásticas. En su plan, la primacía del aprendizaje artístico basada en el despotismo de la copia y la imitación quedaba abolida. En su lugar, se daba prioridad a todo aquello que pudiera poner de manifiesto las dotes individuales de los alumnos: la experimentación formal, la libertad expresiva, la intuición como medio de llegar al conocimiento, el estudio de la naturaleza y sus leyes estructurales, el estimulo de las aptitudes expresivas individuales, etcétera; todo ello en aras de conseguir la auténtica capacidad creativa. De este modo, Ferrant se convirtió en portavoz de la moderna pedagogía artística en España.

El 23 de julio de 1936, en plena Guerra Civil, se creó la Junta de Incautación y Protección del Tesoro Artístico, promovida por la Alianza de Intelectuales Antifascistas. Ángel Ferrant y su hermano Alejandro, entre otros, colaboraron activamente en la Junta Delegada del Tesoro Artístico de Madrid. El 11 de enero de 1938 el gobierno de la República, desde su sede en Barcelona, publicó una Orden ministerial por la que Francisco Javier Sánchez Cantón cesaba como subdirector del Museo del Prado, siendo sustituido por Roberto Fernández Balbuena, quien entonces era presidente de la Junta Delegada de Incautación. Ésta pasó entonces a ser presidida por Ángel Ferrant. En enero de 1938 Fernández Balbuena desempeñaba también el cargo de delegado de Bellas Artes en el Ministerio de Instrucción Pública. A primeros de febrero de 1938 Alejandro y Ángel Ferrant, con Roberto Fernández Balbuena, realizaron un viaje a Barcelona, súbitamente y sin explicar los motivos, dejando truncada a la Junta hasta junio de $1938^{1}$. Durante este periodo, el gobierno de la República confió a Ángel Ferrant tomar parte como miembro de una Comisión para la reforma de las Escuelas de Bellas Artes. Ferrant gozaba de un merecido prestigio en materia de renovación educativa. El gobierno republicano valoraba su gran vocación por la enseñanza, su grado de responsabilidad, su formación y sus conocimientos en materia de pedagogía; además, conocía su actitud abierta y su talante aperturista y colaborador. Hay constancia de la demanda hecha por José Renau Berenguer, Director General de Bellas Artes, solicitando la colaboración de Ferrant; así figura en una carta fechada el 1 de diciembre de 1937, firmada por Renau y remitida desde Barcelona a Roberto Fernández Balbuena. En la misiva, Renau le avanza, extraoficialmente, la decisión tomada desde el Ministerio de Instrucción Pública y Bellas Artes de crear un Consejo Central de Artes Plásticas para "reorganizar a fondo todas las cuestiones de la enseñanza artística, escuela de Arquitectura, y planes de arquitectura en sí, adoptados al momento" 2 . La importancia política del asunto es acentuada por Renau en su carta; éste llama la atención de Fernández Balbuena y le expresa que considera completamente necesario que Ángel y Alejandro Ferrant viajen a Barcelona para conferenciar con él con vistas a su colaboración en las citadas cuestiones. Además, Renau subraya la vertiginosa importancia de este asunto en su carta: "el ministerio me indica todo esto como de importancia fundamental y me exige la rápida

\footnotetext{
${ }^{1}$ Durante la ausencia de Ángel Ferrant, Matilde López Serrano ejerció como presidenta en funciones de la Junta Delegada de Madrid.

${ }^{2}$ Véase "Carta de José Renau dirigida a Roberto Fernández Balbuena". [Donación Fernández Balbuena Gascón, IPHE (M. C.) Documento n. $\left.{ }^{\circ} 15.\right]$
} 
puesta en marcha de todos estos asuntos. La orden es pues terminante". Al mismo tiempo, deja patente la lealtad depositada en los hermanos Ferrant para el desempeño de dicha ocupación: "Ya sabéis la falta de gente que hay para todo y, además, la falta de gente de confianza, de probada lealtad con la que uno se puede embarcar con todas las consecuencias en las tareas que el momento señala"3.

El traslado a Barcelona y la ausencia de Madrid por parte de los hermanos Ferrant fue muy controvertido, sobre todo entre los miembros de la Junta Delegada del Tesoro Artístico. No obstante, Ángel Ferrant, tras regresar a Madrid, explicó en la reunión de la Junta Delegada del 14 de julio de 1938 por qué él, su hermano y Balbuena viajaron a Barcelona. En el acta de la reunión constan los motivos aducidos por los hermanos Ferrant para justificar dicha marcha:

[...] Su ida a Barcelona podía ser interpretada como un abandono del puesto que ocupaban, aunque hubiera presiones y razones suficientes a favor del viaje; podía asimismo ser interpretada como empeño excesivo de permanecer en Madrid contra todas las razones de que era, a más de amigo, superior inmediato, que alegaba su superioridad y que creía conveniente el viaje hasta el punto de comenzar ellos mismos por dar ejemplo, emprendiéndolo $[\ldots]^{4}$

Ángel Ferrant previó que su estancia en Barcelona sería por poco tiempo, si bien la realidad fue muy distinta; permanecieron allí seis meses. A su llegada a dicha ciudad, se vieron envueltos en una serie de circunstancias adversas. Una de ellas fue la crítica situación registrada por la falta de nombramiento del Director de Bellas Artes. No obstante, otra serie de desavenencias e incidentes retuvieron a los hermanos Ferrant en Barcelona. Una fue la visita al refugio donde se encontraban instalados unos cuadros del Museo del Prado para su examen; otra, más comprometida, fue la referente al decreto según el cual las Juntas del Tesoro Artístico quedaban agregadas a Hacienda y separadas del Ministerio de Instrucción Pública. Esto último suscitó el propósito de dimisión inminente en el cargo de Presidente de la Junta, por parte de Ferrant, circunstancia que no acaeció de inmediato ${ }^{5}$. El riesgo de interpretaciones suspicaces, de recelos y especificaciones escabrosas, ante dicho posicionamiento, obligó a éste a obedecer y a permanecer en su cargo de Presidente, aunque su dimisión no tardaría en hacerse efectiva. Pese a todo, parece claro que la actuación de Ferrant y de su hermano en Barcelona fue motivo de elogio y aprobación por parte de los mandos gubernamentales republicanos.

Como ya se ha indicado, uno de los motivos por los que se requiere la presencia de Ángel Ferrant en Barcelona, en 1938, es el de su participación como miembro de un proyecto destinado a fomentar la reforma de las enseñanzas artísticas y la Arquitectura. Durante aquella estancia barcelonesa, Ferrant redacta un admirable trabajo que lleva por título La educación en arte y

\footnotetext{
3 Ángel Ferrant siempre se mantuvo fiel a los ideales republicanos. En cambio, su hermano Alejandro se mostró rápidamente afecto al franquismo. Éste, tras finalizar la contienda, colaboró con el gobierno de Franco afrontando tareas y responsabilidades propias de su profesión de arquitecto. Además, durante el tiempo que permaneció en la Junta, su conducta fue calificada de "favorable a los propósitos que guiaron al Gobierno de la España Nacional en 1938", según consta en un informe elaborado por Pedro Muguruza Otaño, Comisario General del Servicio Militar de Defensa del Patrimonio Artístico Nacional, firmado el 14 de octubre de 1939. [Véase "Certificado realizado por Pedro Muguruza a Alejandro Ferrant", Expediente 35-2, IPHE, Madrid.]

${ }^{4}$ Libro de actas de la Junta Delegada del Tesoro Artístico de Madrid, fols. 35-37v. ${ }^{\circ}$ IPHE, Madrid.

${ }^{5}$ Con fecha 20 de julio de 1938, Antonio de la Cruz, Delegado de Bellas Artes del Ministerio de Instrucción Pública y Bellas Artes, confirma y ratifica a Ferrant su confianza en el desempeño del cargo de Presidente de la Junta Delegada del Tesoro Artístico de Madrid, no encontrando motivos suficientes que justifiquen su dimisión, "antes bien, creyendo necesaria su permanencia en dicho puesto". [Expediente personal de Ángel Ferrant (Leg. 5). IPHE, Madrid.]
} 
sus tangencias con la enseñanza general ${ }^{6}$. El aspecto que él desarrolla es la reorganización de la Escuela de Bellas Artes. Sin embargo, Ferrant no estudia de forma aislada este Centro educativo; en su ensayo, vincula los estudios de Bellas Artes a otras disciplinas artísticas y educativas. Sus orientaciones didácticas están fundamentadas en el institucionismo, cuyos ideales ejercieron una notable influencia en los círculos más avanzados del país ${ }^{7}$. En la redacción de su trabajo, Ferrant menciona distintos ámbitos que atañen a la educación artística. Estudia extensamente y con detalle las diversas competencias en que puede diversificarse la enseñanza del arte, según sus respectivas esferas. Examina, asimismo, el papel que asumen en cada centro, en virtud del contexto y de la generalidad de la educación. Analiza progresivamente las Escuelas de Bellas Artes, el Conservatorio de música, la Universidad, los Institutos de enseñanza media, las Escuelas de Artes y Oficios, las Escuelas de Trabajo y las Escuelas primarias. La necesidad de una presencia activa del arte en la vida cultural y social es parte fundamental del mensaje del ensayo de Ferrant. En el mismo, hace también un estudio certero sobre la labor que ha de desarrollar el profesor, en particular la figura que él designa como artista-profesor, haciendo hincapié en la exigencia de su fusión y en la importancia de su formación. Por último, no olvida reflexionar acerca de la totalidad del proceso educativo y de la toma en consideración del sentir por medio del arte. Dos gráfi$\cos ^{8}$ de gran riqueza plástica, diseñados por Ferrant, acompañan al texto; ambos complementan el desarrollo del discurso ${ }^{9}$. Los dos documentos se integran y superponen. En el primero -ilustrado con tinta china, tinta blanca y lápiz sobre cartón blanco-, aparecen representadas, a modo de forma abierta, las tres etapas de la cultura - primaria, secundaria y universitaria-. En cada una de ellas, Ferrant anota breves reflexiones escritas, en función del nivel educativo, con indicación a derecha e izquierda de los dos sentidos educacionales que reclama la doble lucidez con que se manifiesta el espíritu ${ }^{10}$. Se refiere, por un lado, a la racional-formación perceptiva, educación del juicio en función racional, e inhibición de la personalidad-; y por otro, a la intuitiva -formación intuitiva, educación del juicio en función sensorial y predominio de la personalidad-:

[...] A ambos lados del eje en el gráfico I aparece el campo de actividad que aquél divide en las dos zonas en que por tendencia natural habría de moverse el estudiante para acabar polarizándose en una de ellas al tomar profesión y situarse, por último en el punto en que, por la potencialidad de su vocación, puesta a prueba, habría de corresponderle. Se sobreentiende que la obligatoriedad con que se señalan las etapas primaria y secundaria es circunstancial. Ella dependería de los medios con que se contase para poderla establecer según se indica. No obstante, se hace constar ese carácter obligatorio, porque no corresponde a una utopía sino a una meta, todo lo lejana que se quiera, pero que es imprescindible divisar para emprender la ruta verdadera $[\ldots]^{11}$.

\footnotetext{
${ }^{6}$ Ferrant conservó para sí mismo una copia mecanografiada de dicho trabajo. Encabezando la primera página aparece una anotación suya manuscrita a lápiz, "Época de Barcelona", en alusión al periodo que cubre los seis primeros meses de 1938. [Véase La educación en arte y sus tangencias con la enseñanza general, en Museo Patio Herreriano, Colección Arte Contemporáneo, Fondo Ángel Ferrant (F. F.- TEX. Fe. 1 - 736).]

${ }^{7}$ Cfr. Giner De los Ríos, Francisco, "Sobre reformas en nuestras Universidades" [1916], en Sobre Educación y Enseñanza (Obras selectas), Austral Summa, Madrid, 2004, pp. 563-658. También Asenjo FernÁndez, I., “Ángel Ferrant y los ideales institucionistas" [2004], en BILE, vol. 56, pp. 95-108, Madrid.

${ }^{8}$ Véase "Gráfico n. ${ }^{0} 1$ del texto La educación en arte" [en Museo Patio Herreriano, Colección Arte Contemporáneo, Fondo Ángel Ferrant (F. F.- PED 2 - 966)].

${ }^{9}$ No fue la primera vez que Ángel Ferrant complementaba un texto didáctico con un gráfico de elaboración propia. En 1931 lo hizo con su ensayo didáctico Diseño de una configuración escolar. [Véase "Gráfico del texto Diseño de una configuración escolar”, en Museo Patio Herreriano, Colección Arte Contemporáneo, Fondo Ángel Ferrant (F. F.- PED 1 - 965).]

${ }^{10}$ Anotación manuscrita realizada por Ferrant en la base del gráfico.

11 "La educación en arte...", doc. cit., p. 22.
} 


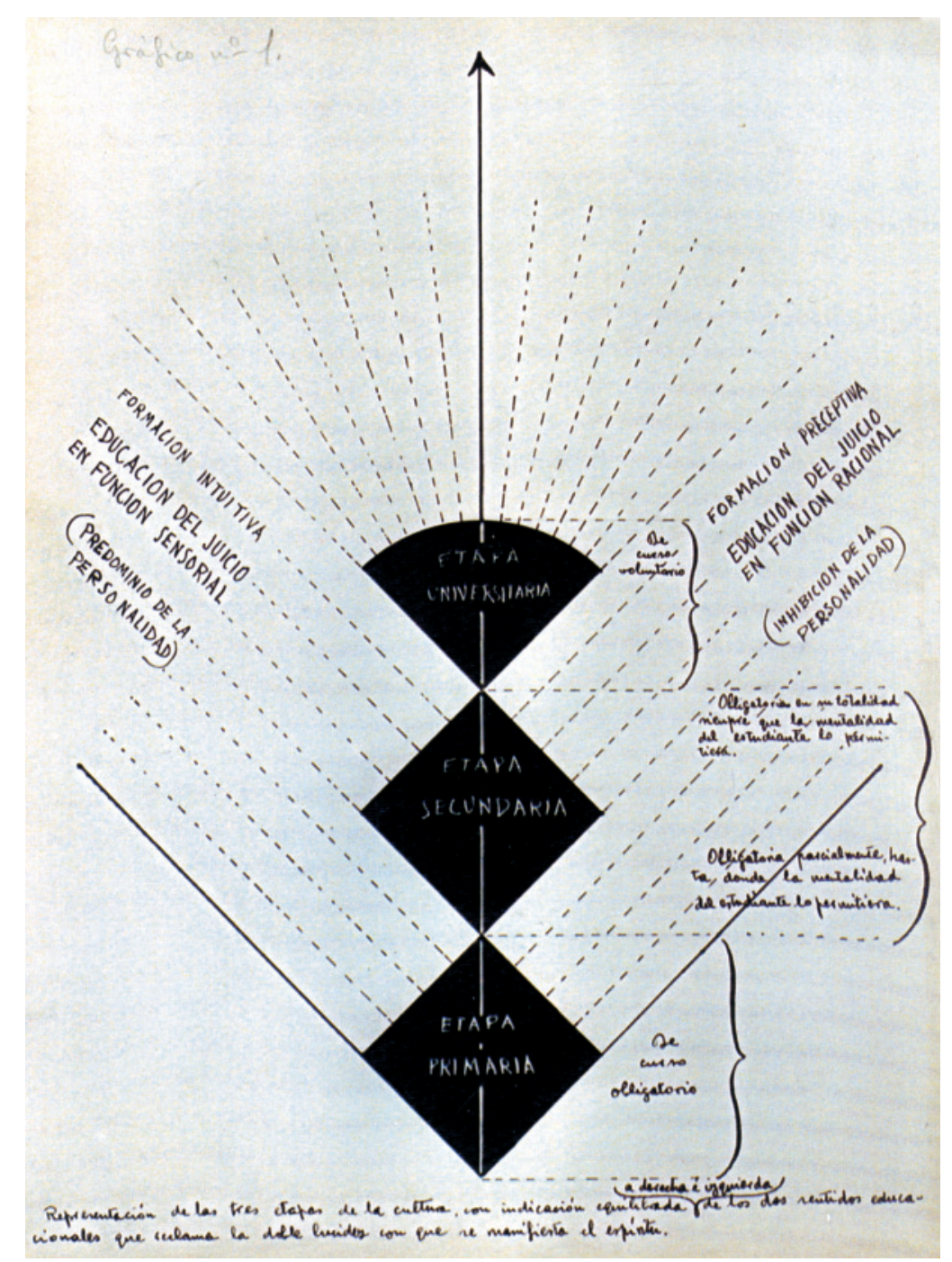

Fig. 1. Gráfico n. ${ }^{\circ} 1$ de Ángel Ferrant para La educación en arte y sus tangencias con la enseñanza general.

En el segundo documento gráfico están representados los Talleres, las Escuelas especiales, las Escuelas de Trabajo y las Escuelas de Artes y Oficios. Este gráfico, delineado con tinta negra y blanca sobre papel vegetal, va unido al anterior en su parte superior. La articulación propuesta por Ferrant en su estudio se puede apreciar gráficamente cuando se superponen los dos dibujos, surgiendo entonces la complementariedad cultural entre la educación general y la propiamente artística, proyectada por él. Tres unidades, con carácter de conjunto formal cerrado, aparecen simbolizadas en el segundo documento. La primera unidad, con forma de octante de luna que mira hacia abajo, acoge a las Escuelas especiales y los Talleres. Las otras dos, simbolizadas por sendos cuadrados superpuestos, representan a las Escuelas de Trabajo y las Escuelas de Artes y Oficios; dichos cuadrados están divididos en líneas paralelas, dependiendo del nivel profesional alcanzado; en el gráfico aparecen señaladas asimismo las dos direcciones -espontánea o encauzada- que han de acompañar a cada una de las vocaciones, para lo cual su autor emplea líneas discontinuas de trazo diferenciado: 
[...] En el gráfico II pueden apreciarse a los lados del eje las dos orientaciones en que concebimos deslizándose la vocación. O sea, el impulso vocacional libre, espontáneo, incontrolado, que sigue su curso natural, si bien encaminándose hacia un objetivo del que fatalmente se desvía por la falta de aquellos conocimientos que han de imprimirle rumbo verdadero. Y el impulso vocacional canalizado, encauzado en virtud de la organización de aquellos conocimientos cuya adquisición, racionalmente dosificada, según el grado e índole de la capacidad individual, da lugar a la coincidencia positiva final de la vocación con la profesión $[\ldots]^{12}$.

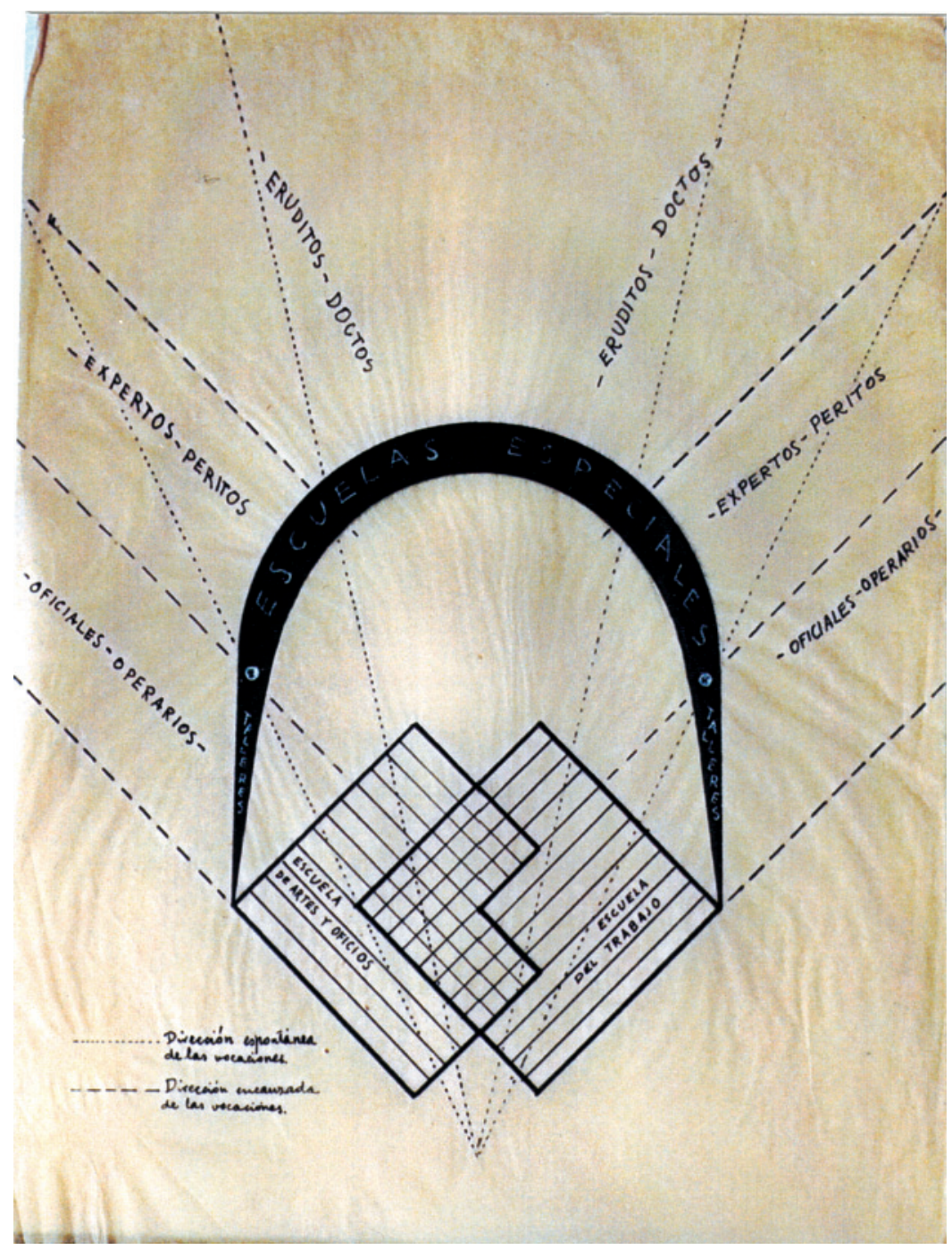

Fig. 2. Gráfico n. ${ }^{\circ} 2$ de Ángel Ferrant para La educación en arte y sus tangencias con la enseñanza general.

12 Ibidem, p. 22. 
En el preámbulo del trabajo, Ferrant esclarece la necesidad de abordar el estudio de la Escuela de Bellas Artes junto a otras esferas del mundo de la enseñanza, dado el carácter de unidad y correlación que, a su juicio, ha de tener la educación:

[...] Dentro del área viva en que ha de dibujarse el perfil cultural del pueblo español, cae, a nuestro juicio el problema de su educación en arte. El examen de este problema hubimos de abordarlo situados, si bien transitoriamente y como meros espectadores en la Escuela de Bellas Artes. En rigor fuimos allí con una misión circunscrita a la reorganización de dicho centro. Pero fácil será comprender que esta escuela -como tantas otras instituciones- no puede concebirse debiéndose a sí misma; es decir que no podría funcionar bien si se la considerase aislada o independiente. A nuestros ojos al menos, su vitalidad, ha de depender en gran parte, de multitud de articulaciones y contactos. $Y$ es por lo que al recaer en la Escuela de Bellas Artes, nos vimos obligados también a fijarnos en otros organismos; en las Escuelas de Artes y Oficios, en las de Trabajo, en el Conservatorio... etc. ${ }^{13}$.

Seguidamente, Ferrant pasa a analizar la Escuela de Bellas Artes. Debido a las características que ésta ostenta y a la cohesión que ha de primar en la misma, el autor comienza su disertación precisando por qué esta enseñanza ha de enfocarse con un talante diferente al de cualquier otro centro transmisor de una disciplina. Encabeza su razonamiento tomando como ejemplo a la Pintura, a la que considera como un todo homogéneo e indivisible. En su opinión, en esta materia, se ha de entrar de lleno desde un principio:

[...] sencillamente porque no se requiere para poder practicarla, estar antes en el secreto o en posesión de determinados conocimientos de carácter científico (cual ocurre con la Arquitectura).

Sin duda, todo conocimiento -y algunos en particular más que otros-ajeno a su esencia, le será favorable si se aprende bien; pero el hecho es que, lo que en la Pintura concretamente se encierra no puede disgregarse si es que se mira la Historia con los ojos abiertos. Por otra parte, la Pintura considerada en abstracto (como cosa mental, según frase de Leonardo) no puede ser concebida igualmente por todas las cabezas. Por consiguiente, es un disparate que, en una Escuela de Pintura, haya un profesor de ropajes, otro de colorido, otro de procedimientos,... etc.

Eso, es mucho más ilógico que el que las cuatro reglas, nos fuesen enseñadas por otros tantos profesores de Aritmética $[\ldots]^{14}$.

Se disloca la vocación del alumno, añade, tirando en tantas direcciones. Para establecer sus propósitos, Ferrant argumenta en favor de la individualidad y el principio de idiosincrasia en el artista. No obstante, no olvida perseverar en la necesidad de no cerrarse en los límites del terreno exclusivamente artístico. Su objetivo apunta más bien hacia la necesidad de abrirse y de manifestarse, no sólo en la relación que ha establecerse entre profesor y alumno, sino también entre la enseñanza de las Bellas Artes frente a otros ámbitos de la enseñanza:

[...] Porque, se habla de tendencias, y hasta se piensa en la posibilidad de reunirlas todas, a fin de que se combinen eficazmente, en la inocente suposición de que cada artista

\footnotetext{
${ }^{13}$ Ya que, en definitiva, son asimismo miembros o zonas integrantes de un solo conjunto orgánico, al cual ha de ajustarse armónicamente. Porque, de qué serviría obstinarse en cuidar una parte del cuerpo que se resintiera de un daño cuya causa estuviera en otra. (Nota del autor.) Ibidem, p. 1.

14 Ibidem, p. 2.
} 
puede sentir unido su espíritu al de otros compañeros. Pero hay que desengañarse de eso, pues en la conciencia del artista, ni pesa, ni cabe más que una tendencia: la suya. $Y$ de no ser así, no se daría el artista sino el diletante o el caprichoso catador de fruslerías, transigente y acomodaticio ni siquiera por imperativo de sociabilidad, sino a fuerza de ser frío e indiferente, condiciones éstas francamente negativas en el artista.

Si en Pintura no desempañara un importante papel, factor tan decisivo como la personalidad -y la personalidad que se aprecia en el modo de hacer, es el reflejo del modo de pensar, o más bien, de ser-, podría confiarse en lograr la cohesión de un profesorado de pintores como se logra la de un profesorado de ciencias. Pero, la cohesión que debe buscarse en una Escuela de Bellas Artes, no es precisamente la de sus profesores-pintores, sino la de éstos, con aquellos otros que no sean pintores; o lo que es lo mismo: la de la Pintura con cuanto sea favorable a su eclosión. Y después, la de cada profesor con sus alumnos. $[\ldots]^{15}$

En la Escuela Superior de Artes Plásticas, así denominada por Ferrant, habrían de figurar los profesionales - pintores, escultores,...- de personalidad más destacada. Estos profesores acogerían al número de alumnos que las circunstancias y las normas así lo aconsejaran, y se desenvolverían, apunta Ferrant, ajustándose a las realidades que se nos presentan. Los profesores serían propiamente artistas, y no actuarían, en su parte del proceso de formación escolar, con una aportación parcial y desdoblada en diversos aspectos especiales de su disciplina. Cada profesor, añade Ferrant en su escrito, estaría obligado a desarrollar sus cursos, dentro de un sistema cíclico, personal y total; es decir, completo y según su iniciativa, pero ajustado a determinados periodos de carácter general, cinco en total. En cuanto a la Dirección de la Escuela, Ferrant entiende que ésta habría de recaer en quien poseyese las condiciones necesarias para coordinar el funcionamiento de las clases -sin ser necesariamente profesor o especialista en un arte determinado-, en alguien a quien se supiese o se presumiese que poseía las condiciones necesarias para coordinar el funcionamiento de las clases o imprimir a la Escuela la mayor vitalidad, sobre la base de un criterio que abarcara con la mayor amplitud los valores contemporáneos correspondientes a este centro ${ }^{16}$. Respecto a la distribución de los alumnos en las clases de los profesores-artistas, Ferrant propone tener en cuenta: primero, los deseos del alumno; segundo, sus antecedentes; y tercero, los dictámenes de la Dirección y el Claustro. Aclara, no obstante, que el funcionamiento del proceso escolar habría de permitir que el estudiante pudiera pasar a depender de un profesor a otro; aunque no se detiene en completar pormenores y detalles, pues considera que son más propios de un plan reglamentado que no es propósito de su estudio.

En los cinco los periodos escolares, presentados por Ferrant, encontramos enunciaciones que ya habían sido postuladas por él con anterioridad en otros proyectos educativos: la importancia de la enseñanza intuitiva y no directiva, la no mezcolanza de la obra de los museos con la apreciación de la labor escolar, el fin expresivo del empleo de las técnicas, la importancia de la comunicación profesor-alumno, el predominio de la pureza de la idea frente al alarde técnico, la eficacia de la autoformación escolar en oposición a la frecuente desviación autoformativa sufrida en periodos preescolares, la importancia de los estímulos y sensaciones frente a los principios o doctrinas, etcétera. Las normas en que habrían de orientarse los cinco periodos escolares citados se resumen en los siguientes puntos:

$1^{\text {er }}$. periodo. Aspiración a una expresión plástica nativa. Trabajos escolares elementales encaminados a averiguar el grado de autoformación del estudiante, con los que descubrir sus

\footnotetext{
15 Ibidem, pp. 2-3.

16 Ibidem, p. 4.
} 
facultades nativas. Ferrant propone desarrollar la intuición rechazando las explicaciones apriorísticas. Se busca la percepción de los valores constantes del arte en las labores escolares, sin mezclar en su apreciación las obras de los museos. Las técnicas, por su parte, han de poseer carácter primario.

2. ${ }^{\circ}$ periodo. Trabajos en los que se asocien formas de una realidad imaginada por los alumnos y profesor. Se plantea la depuración del sentido plástico innato y la autoformación escolar. El alumno se auxilia con modelos y con referencias verbales, tan sólo se han de citar algunos ejemplos históricos y prácticas aclaratorias. Lejos de las doctrinas, la atención se centra en lo sensitivo y se aleja de las ingerencias racionales. Las nociones técnicas, apunta, han de ser únicamente vehículo de la expresión.

$3^{\mathrm{er}}$. periodo. Labor analizada y consciente. Sin olvidar el enriquecimiento del sentido plástico innato, éste se ha de desarrollar con teorías capaces de canalizarlo en una dirección reflexiva que asegure su evolución. Ferrant propone, pues, analizar la composición, estudiar la organización de las formas, investigar las estructuras vivas y vivientes y adquirir los conocimientos geométricos y científicos necesarios para el arte. También plantea la realización de prácticas rigurosas de la técnica predilecta en función expresiva. Asimismo, solicita que el alumno sea autocrítico y crítico con el primer periodo escolar. Ferrant establece, además, que en este periodo se lleven a cabo los primeros trabajos en colaboración.

4. ${ }^{\circ}$ periodo. Trabajos de iniciativa escolar. Los alumnos, en colaboración, realizan obras y proyectos, estudiando el entorno y el medio social de su emplazamiento. Ferrant propone que se efectúen estudios comparativos de las creaciones plásticas del pasado y se relacionen con las recientes. Para ello, añade, es necesario estudiar la Historia del arte y utilizar una adecuada bibliografía del arte actual.

5. ${ }^{\circ}$ periodo. Emancipación del grupo y del individuo. Los alumnos adquieren plena independencia en la dirección de sus trabajos. Sus proyectos y realizaciones -individuales o colectivas- se someten a la crítica -individual o del grupo-. Al igual que en los actuales cursos de doctorado, los alumnos, orientados por un profesor, llevan a cabo estudios especiales de aquellas ideas, autores o periodos del arte antiguo o moderno voluntariamente escogidos por ellos. Además, han de organizar exposiciones y actos públicos ${ }^{17}$.

Pensando quizá en el escaso nivel formativo y académico que poseían entonces algunos estudiantes de Bellas Artes, Ferrant cree que es pertinente que dicho alumnado curse con anterioridad a su ingreso en la Escuela Superior la preparación obligatoria especial que se acordase en las Escuelas de Artes y Oficios. También estima conveniente que los alumnos de Bellas Artes cursen obligatoriamente el bachillerato, o parte de él, en el Instituto; además, el escultor sostiene que: algunas asignaturas o cursos deberían exigírsele a su ingreso en la Escuela especial, así como otras ú otros a su salida de ella. Por último, Ferrant exhorta al alumno que sale de la Escuela a permanecer atemperado en la mayor amplitud posible a las actividades de otros centros -Conservatorio, Universidad, etc...-. ${ }^{18}$

Después de analizar los estudios de Bellas Artes, Ferrant se centra en la enseñanza musical y el Conservatorio ${ }^{19}$. Comienza advirtiendo del riesgo que puede suponer la exclusividad de dicha profesión, a la vez que dispensa al Conservatorio una función de carácter social:

[...] porque, el arte, exige, además de la formación del profesional, la preparación del público que lo disfrute. Y, probablemente, es la música, uno de los estímulos estéticos

\footnotetext{
17 Ibidem, pp. 5-7.

18 Ibidem, p. 8.

19 Es destacable señalar que Ángel Ferrant recibió formación musical desde niño.
} 
más apropiados para la niñez como por frecuentes casos de precocidad se nos presenta, así como también por la huella verdaderamente imborrable que constituyen los recuerdos musicales y las canciones de infancia.

Iniciarse en la música cuando se tiene uso de razón o se llegó a la adolescencia, viene a ser lo mismo que empezar a practicar la gimnasia o a conocer un idioma en edad madura $[\ldots]^{20}$.

Se lamenta de que la instrucción musical no figure en el conjunto de la cultura general, como los estudios del bachillerato, a pesar de ser, anota, un sentimiento dentro de los gustos de la cultura popular. Insta, pues, a que se le preste la debida atención. Para ello, Ferrant propone la formalización de unas misiones culturales de música, coordinadas con el régimen de las escuelas e institutos, bajo la organización del profesorado del Conservatorio y el alumnado de este centro; asimismo, sugiere un proceder análogo con la Escuela de Declamación del Conservatorio. Piensa, además, en la conveniencia de que no debería transcurrir un curso sin que éstas dejasen de presentarse al público para verificar sus prácticas, puramente escolares, ante espectadores invitados, para demostrar la obtención de sus resultados en actos de conjunto escénico. Ferrant señala también la detestable incomunicación en que se forman los distintos especialistas en arte:

[...] Los estudiantes de Música, los universitarios, los de Bellas Artes, etc., habrían de concertar unidos a los de la Escuela Teatral, y orientados por el respectivo profesorado, la celebración de dichos actos, en los que la colaboración habría de abarcar todo cuanto en el escenario converge y las escuelas oficiales pudieran aportar; y en lo plástico puede decirse que desde el más insignificante programa impreso por la Escuela de Artes Gráficas hasta la realización de los proyectos de figurines y decorado. [...] $]^{21}$.

Ferrant analiza a continuación los estudios de la Universidad. Su reseña es breve, pero eficaz. Admite que es aquí donde se fragua con mayor probabilidad el hombre culto que se infla de sabiduría y se despega de la tierra. Éste es, afirma en su escrito, el que adquiere la manía del saber y el que se abre un único camino: el del conocimiento a través de un esfuerzo intelectual a ojos cerrados, y a medida que lo va recorriendo se le atrofian los sentidos cuya función habría de serle imprescindible, ocaso precisamente para la misma disciplina a que se consagró 22 . Ferrant manifiesta que es raro encontrar verdaderos expertos entre las doctas figuras del personal universitario. En su opinión, en las universidades se prescinde de los contactos experimentales, aquellos que pondrían en uso y a prueba la cultura adquirida, en los cuales habría que cifrar la confianza en la más auténtica profundidad de ciertos estudios sobre todo cuando éstos se refirieran a materias y a hechos ${ }^{23}$. Considera asimismo que este aspecto es una cuestión de ambiente y de ventilación. Cree, pues, que la permanencia en el encierro no es favorable a la sabiduría sino a la pedantería, y ha de evitarse. Por tanto, sostiene que todo estudio que sobre Arte se realice en las universidades, bien por sus catedráticos o por sus estudiantes, habrán de mantener las relaciones pertinentes con los respectivos de la Escuela Superior de Bellas Artes, del Conservatorio o de los núcleos de la juventud dedicada a las artes profesionalmente. A tal fin, añade, los respectivos centros fijarán, en sus planes de estudios, tareas conjuntas -debates, exposiciones, conferencias- en provecho de ambos.

Al examinar los Institutos de enseñanza media, Ferrant considera que es un enorme disparate creer que todo se puede aprender en los libros, ya que su contenido, apunta, se volatiliza en gran

\footnotetext{
20 "La educación en arte...", doc. cit., pp. 8-9.

21 Ibidem, pp. 9-10.

${ }^{22}$ Ibidem, p. 10.

23 Ibidem, pp. 10-11.
} 
parte, tan pronto como ha sido recogido por el escolar. Las experiencias o prácticas que en ellos se pueden verificar, añade al respecto, son tan pobres que no permiten aclarar las teorías, y, menos aún, despertar un interés por la investigación basado en ellas. En su opinión, padecemos los efectos de una cultura desorbitada por los libros, "cuyo fruto más peligroso es ese hombre pozo de ciencia que es el que más sabe de aquello que los demás no ignoran mientras él lo desconoce" "24; dicho razonamiento guarda afinidad con los postulados institucionistas ${ }^{25}$. No obstante, Ferrant, consciente de la celeridad de los tiempos, se muestra visionario al plantear la rivalidad que ofrece la cultura de la imagen -proporcionada por el Cinema- frente a la cultura de la letra. Carecemos de una cultura por la acción -escribe Ferrant-, es decir, por la experiencia y, sin duda es el cine el grito que con más fuerza despertó nuestra avidez por estudiar las cosas en vivo, es decir sintiendo su contacto, viviéndolas, experimentándolas ${ }^{26}$. Solicita, pues, la modificación radical del plan de estudios de los institutos. Hay que corregir, apunta, el desequilibrio existente entre el conceptualismo memorista y la falta de los hechos reales que lo vivifiquen y lo comprueben, sin crear confusión de ideas. Su propuesta se centra en acompañar la teoría con la práctica y en hacer que los alumnos se entreguen a una labor propiamente activa visitando diversos lugares -agrícolas, científicos, artísticos, talleres, laboratorios, etcétera-. Respecto a los profesores de Dibujo en los institutos, mantiene que los mismos, con el fin de atender bien tal enseñanza, se incorporen a las Escuelas de Artes y Oficios, a las cuales debería asistir obligatoriamente el alumno de bachillerato, a fin de cursar con la debida extensión y formalidad y en el debido ambiente la asignatura de referencia ${ }^{27}$.

Seguidamente, Ferrant centra el estudio de las Escuelas de Artes y Oficios explicando dos maneras de destruir: la del que destruye por ignorancia y la de los seudocultos. Para argumentar la primera, cita la barbarie ocasionada por los incultos durante la Guerra Civil -la misma época en la que redacta este estudio-; en este sentido, manifiesta, a veces se negó la entrega de muebles y cuadros de verdadero valor a la Junta de Incautación por temor a ser destinados a combustible. Para ilustrar la segunda forma de destrucción, la de los seudocultos, Ferrant menciona la carencia de gracia y la falta de sentido práctico de las reformas urbanas, los edificios y los monumentos modernos esparcidos por España. Lo que ambos casos nos demuestran -escribe- es: que la incultura y la seudocultura se confunden en el estrago, en la barbarie, en el salvajismo. [...] Es el pueblo [...] quién reclama la comprensión de ese tesoro por medio de una educación a la que tiene derecho, mientras que, intacto, lo conserva pulcramente bajo su custodia $[\ldots]^{28}$. Según Ferrant, las Escuelas de Artes y Oficios son las llamadas a extender estas enseñanzas, difundiéndolas y ejerciendo su influjo sobre las masas de juventud de la más diversa procedencia.

Ferrant estudia también las Escuelas de Trabajo. Es imposible, indica el escultor en el documento, que todo aquel que carezca de la sensibilidad necesaria para percibir la obra de arte se percate del respeto que merecen y del alcance que tienen los juicios del que aprecia su valor. Por el contrario, afirma, quien es sensible al arte, reconoce normalmente el valor de las percepciones racionales de los demás. Según Ferrant, las artes plásticas no se pusieron al alcance de ser comprendidas por cualquiera, en virtud de convencionalismos pueriles; por ello, asegura, el arte es para todos, pero no todos son para el arte. Por tanto, éste es el riesgo que presenta, a su juicio, la fusión entre Escuelas de Trabajo y Escuelas de Artes y Oficios; no obstante, se declara partidario de su existencia separada, si bien, funcionando en estrecha relación. Ferrant

\footnotetext{
24 Ibidem, p. 12.

${ }^{25}$ Cfr. Giner DE Los Rios, Francisco, "Sobre la educación técnica en la Institución Libre de Enseñanza" [1886], en Sobre Educación y Enseñanza, op. cit., pp. 312-333.

26 "La educación en arte...", doc. cit., p. 12.

${ }^{27}$ Ibidem, p. 13.

28 Ibidem, p. 14.
} 
afirma que ambas Escuelas tienen en común el trabajo manual -la artesanía-, por lo demás se diferencian. A su juicio, el valor de la artesanía estriba en la perfección de su técnica manual. Así pues, el objeto de las Escuelas de Artes y Oficios es alcanzar el grado de perfección técnica justo, mientras que alcanzar el grado de perfección técnica máximo es el objetivo de las Escuelas de Trabajo. Según Ferrant, el arte necesita de la ciencia, pero la ciencia no necesita del arte. No obstante, añade, la expresión de arte reclama muchas veces ese grado de perfección técnica máximo característico de la artesanía correspondiente a las Escuelas de Trabajo; por ello, considera conveniente que algunos alumnos de las Escuelas de Artes y Oficios, en ciertos casos, asistan a cursillos de determinados oficios en las Escuelas de Trabajo. La vida, el hombre, necesita de la ciencia y del arte, sentencia Ferrant.

La última etapa educativa se centra en el estudio de las Escuelas Primarias. La práctica artística, ligada al mundo de la infancia, a menudo fue un tema tratado por Ferrant, quien llegó a ser un experto conocedor del arte infantil. Llevó a la práctica diversas experiencias artísticas con niños, diseñó juegos infantiles, participó en distintos eventos culturales relacionados con el arte infantil, $\mathrm{y}$, asimismo, redactó un buen número de artículos ligados a este tema ${ }^{29}$. Dada la facultad innata del niño para las representaciones plásticas, escribe Ferrant en su ensayo, casi normalmente se nace con dotes para la ejecución de determinados trabajos manuales. Dicha disposición, apunta asimismo, constituye, junto al lenguaje, otro medio expresivo de las ideas e impresiones. Incide Ferrant en la conveniencia de ejercitar esas dotes, conveniencia reconocida por los pedagogos, tanto por su eficiencia pedagógica como por su posible aplicación en el futuro desarrollo de la persona. No obstante, recuerda, en las Escuelas primarias los trabajos manuales se reducen a un pasatiempo superficial sin consecuencias prácticas del que no queda el menor rastro que se ligue a la vida del presente en la memoria del individuo cuando el niño pasó a ser hombre ${ }^{30}$. Para evitar el abandono en que se ven sumidas las experiencias infantiles en las Escuelas primarias, Ferrant sugiere la participación de las Escuelas de Artes y Oficios. Propone, pues, que determinados profesores de cada una de las secciones enclavadas en diversas barriadas de la capital visiten oportunamente el grupo o grupos escolares más próximos. Según Ferrant, los profesores de Artes y Oficios son los más capacitados para descubrir las intuiciones infantiles de carácter plástico; además, con ellos, los niños juegan seriamente al trabajo manual con los elementos materiales adecuados que no pueden existir en una escuela primaria; asimismo, explica Ferrant en su ensayo, los muchachos, insensiblemente se instruyen y adquieren unos conocimientos cuyo interés se ha (de) despertar por la práctica y no por la teoría, por el goce y la ilusión de ver y no por la interpretación exclusivamente mental de aquello que se lee o escucha, por la evidencia

\footnotetext{
${ }^{29}$ Las apreciaciones de Ferrant por el arte infantil se hicieron patentes desde muy temprano. En 1935 diseñó el "Arsintes", un juego de plantillas recortables para niños. Su interés se prolongó en la barcelonesa Escuela del Mar, cuya orientación iba dirigida en la línea de la Escuela Nueva, según los postulados educativos del suizo Adolphe Ferrière. Asimismo, llevó a término iniciativas de actividades de formación para niños de barriadas obreras. Éste fue el objetivo de la Asociación Auxiliar del Niño, creada en febrero de 1935 por iniciativa privada, y de la cual fue su secretario; entre las empresas para las labores de protección de la infancia contaron la creación, en Madrid, de una biblioteca infantil en Vallecas, en junio de 1935, o la puesta en funcionamiento de un Club Infantil en el barrio de Prosperidad, en julio del mismo año, de cuyo taller artístico para niños fue profesor. Con relación a las publicaciones mencionadas, véanse "Resplandor y proyección de los dibujos infantiles", A. C., n. ${ }^{\circ}$ 10, Barcelona, 2. ${ }^{\circ}$ trimestre de 1933, pp. 34-35; "El Taller de los niños", Boletín de la Asociación auxiliar del Niño, 1, Madrid, octubre 1935, 5.n. p. (pp. 7-8); En AA. VV., "El dibujo infantil en la Antigua Escuela del Mar", (Encuesta), Barcelona, Ediciones Garbi, 1949, pp. 3-4; "Sobre la escolaridad del dibujo", Catálogo de la Primera Exposición Internacional y Concurso Nacional de Dibujos Infantiles, Madrid, Centro de Instrucción Comercial, 1953, pp. 3-5; "Del campo plástico de los párvulos", Bordón, Revista de la Sociedad Española de Pedagogía, V, 38, X-1953, pp. 3-5; y "Eclosión y continuidad del dibujo infantil”, manuscrito, de 1953 (estuvo prevista su publicación en Mundo Hispánico).

30 "La educación en arte...", doc. cit., p. 17.
} 
palpable de una función, y no por lo que se deduce o supone de un relato o de una explicación ${ }^{31}$. Además, en opinión de Ferrant, los niños podrían ser acogidos en los diversos establecimientos docentes dedicados a las actividades de tipo manual, no sólo en las Escuelas de Artes y Oficios, sino también en las Escuelas de Trabajo, u otros; ello se haría acorde a un estudio previo de los dibujos o trabajos infantiles realizados, más la información proporcionada por los maestros, de acuerdo con los profesores de las distintas Escuelas.

Ferrant brinda otra parte importante de su estudio a la figura del Artista-Profesor. Admite que éste es un elemento indispensable dentro de la enseñanza general, pero, en su opinión, no existe:

[...] Artista y profesor son términos que, al parecer se contradicen. Indudablemente corresponden a dos tipos de hombre. El artista sigue siendo el hombre de ayer; es el rezagado, el divo, el inconsciente. La corriente del mundo no le arrastra, le azota. El profesor, por el contrario, consciente de su misión y activo, siéntese empujado por la ciencia, e incorporado a la juventud - al mañana-a la que anima; y marcha hacia un fin concreto al ritmo de su tiempo $[\ldots]^{32}$.

Vocación y aptitud, señala Ferrant, son dos factores individuales e indispensables en la formación de un artista. Recalca, no obstante, que la formación de un artista-profesor ha de abrazar, además de aquéllas, el sentido crítico, la experiencia escolar, la fe pedagógica y la actividad en su doble aspecto -docente y profesional-. Con arreglo a ese canon, Ferrant confiesa que no es posible extraer un solo artista que llegue a la talla de profesor. En su sentir, los profesores hubieran de haber recibido instrucciones de artistas-profesores para convertirse fácilmente en ellos; pero también admite que el artista carece de los principios científicos que le ligan a la sociedad sin separarle del sentido del vivir -de ahí su desplazamiento-. Son, pues, dos sentidos educacionales, pero en fusión, los que Ferrant demanda: el puramente intuitivo y el puramente racional. No obstante, apunta, de los artistas por sí solos no surge el profesorado de calidad propuesto; éste hay que formarlo:

[...] Necesidad que se ha dejado sentir indudablemente puesto que no otra interpretación ha de darse a la orientación de los cursos breves ${ }^{33}$ que se celebraron en estos últimos años para la selección del profesorado de dibujo destinado a los Institutos [... $]^{34}$.

Ferrant es consciente de que la tarea de formación que propone es difícil. Cree, sin embargo, que se ha de partir del propósito de fusión de ambos tipos de individuos -pedagogos y artistas-, pese a que, en principio, se encuentren en campos separados; el fin, en definitiva, es conseguir que se compenetren, que caminen juntos y que se crucen sus ideas:

[...] El desarrollo de la transfusión de ideas se habría de verificar a través del juicio que mereciera a los que figuraran en un grupo, el criterio expuesto por los del otro. Opiniones debatidas, conferencias comentadas, problemas estudiados, objeciones interpuestas o planteadas familiarmente, puntos discutidos, críticas, controversias, coincidencias o discrepancias; todo ello, comenzaría seguramente, por divagación y confusión, pero

31 Ibidem, p. 18.

32 Ibidem, p. 19.

${ }^{33}$ Ferrant se refiere a los cursos de formación y selección del profesorado, organizados en España durante la primera mitad de la década de los años treinta. Él fue ponente del Curso Breve de Selección de Profesorado de Dibujo, celebrado en el Instituto Cardenal Cisneros de Madrid en julio de 1936, y del Curso para profesores, celebrado en Barcelona en 1933.

34 “La educación en arte...", op. cit., p. 20. 
acabaría, probablemente, con precisión y claridad, y daría lugar a que se destacasen las personas que por sus afinidades de pensamiento debieran unirse al final para constituir el grupo definitivo, instructor de aquellos artistas que pretendieran dedicarse a la enseñanza.

Tal sistema selectivo, difiere mucho del tradicional nombramiento de personas que sin haberse visto en la vida, se consideran en la imprescindible obligación de tenerse que entender de pronto, obedeciendo un mandato, con quien no hubieran podido entenderse jamás $[\ldots]^{35}$.

Dado el fin perseguido en su propuesta de modalidad selectiva, Ferrant considera improcedente su semejanza con las oposiciones. La suya, al contrario, tiene apariencias de congreso, de asamblea, de junta, de cursillo o de tertulia. Ferrant plantea que cada profesor elija a un artista y cada artista a un profesor, constituyendo con cada dos personas tantas direcciones de instrucción profesional perseguida como se requiriese. Cada pareja, escribe Ferrant, resumiría escritas las ideas intercambiadas en sus entrevistas, divulgándolas posteriormente en un folleto; después trazarían el programa de los estudios que habrían de cursarse y señalarían las colaboraciones que considerasen pertinentes para el desarrollo de dichos estudios.

La última parte de este estudio está destinada a reflexionar sobre la totalidad del proceso educativo. Uno de los problemas que Ferrant advierte es la falta de una educación cultural básica en la que todos los individuos se vean inmersos. Su argumento no se reduce a dotar a cada individuo de los conocimientos que su profesión requiere, pues, afirma, lo condenaría a la bestialidad; asimismo, tampoco a que cada individuo llegue a desempeñar las funciones más acordes con su vocación, pues, en su opinión, abundan los aficionados con título. Para Ferrant, el planteamiento es un problema de aptitud y de educación general, que habría de iniciarse en la instrucción primaria y finalizar cuando la vocación y capacidades del individuo determinasen:

[...] El problema cultural debe enfocarse en el sentido de que los individuos más aptos para cada función sean los que lleguen a desempeñarla. Y para eso es absolutamente indispensable, someter a todos -o a la mayoría que se pueda- a un periodo de educación general, intensamente activo y experimental en el que lo sensorial se trabe con lo preceptivo. Lo que se necesita es establecer los cauces en que se recoja la fatal expansión de las capacidades, vocaciones y aptitudes, para evitar que se desborden, irritadas en su impetu al sentirse injustamente reprimidas, degenerando en energía negativa $[\ldots]^{36}$.

Ferrant propone que tras finalizar la educación general se inicie la educación profesional, así como el acceso a talleres y Escuelas especiales -universitarias y no universitarias-. Sobre la base, pues, de la cultura general adquirida dentro de las líneas mencionadas, la valía personal del individuo sería la que caracterizase la profesión, y no la profesión o el título profesional lo que caracterizase al individuo. Añade también otra ventaja de este sistema, la de que el individuo derivado hacia una profesión elemental posea los conocimientos exigidos en la suya y también otros asimilados por su vocación, los cuales, en palabras de Ferrant, le harían sentirse ligado a las otras profesiones, al mismo tiempo que capacitado para reconocer, tanto el valor de la obra ajena como el grado de colaboración de la propia ${ }^{37}$. Asimismo, considera equivocado el sistema por el cual las luces del individuo resplandecen iluminando un solo sector profesional, aquél en el cual encaja, pues corta el paso al entendimiento y lo encierra en una falsa raciona-

\footnotetext{
35 Ibidem, p. 21.

36 Ibidem, p. 23.

37 Ibidem, p. 24.
} 
lización del trabajo. Según Ferrant, una gran parte de las distintas manifestaciones naturales y espontáneas que manifiesta el individuo, de niño o de muchacho, son abandonadas en función de su vocación dominante, porque ni figura en el correspondiente recorrido escolar ni cae en la línea profesional que se le marca. Con este sistema, asegura Ferrant, únicamente se lograrán profesionales estándar, o en serie, y no los profesionales que habrían de ajustarse a la naturaleza del individuo que los encarnara, malogrando, pues, lo mejor de cada profesional, es decir, su idiosincrasia: la adición a la materia prima de su espiritualidad, de ricas sustancias humanas por haberlas considerado superfluas. "Llega a ser lo que eres", dijo Píndaro ${ }^{38}$. Por otra parte, su reflexión acerca del papel que ha de desarrollar el arte en la educación -y la educación en el Arte- va encaminada a considerar el arte, no como un lujo superfluo, sino como una carencia que se precisa para los que lo necesitan:

[...] Mas, ¿cómo confiar en obtenerlo si los que nacen con ojos que ven y oídos que escuchan, los capaces de sentir y de padecer la ingratitud o el arañazo de la torpe expresión imaginativa, son empujados por los ciegos y sordos dentro de una misma línea general escolar en la que acaban por insensibilizarse? Habría que empezar por educar a los educadores. A aquellos que al parecer, no necesitan más que lo superfluo sin distinguir los fines de los medios [...]. A nuestro paso por las Escuelas se nos ha mostrado la necesidad de ganarnos la vida. Pero no la necesidad de sentirla. La vida, ese fenómeno total que nos intriga tan pronto como adquirimos conciencia de existir no se nos explicó satisfactoriamente. En los hechos escolares, rara vez nos hemos tropezado por propia experiencia con la revelación del secreto que nos atrae, o con la satisfacción apetecida inconscientemente.

Se nos marca una línea en la que casi todo tiene lugar a destiempo; en la que casi todo se explica pero nada se experimenta; en la que la mejor parte sustantiva se toma por adjetiva y se omite con desprecio. La práctica vendrá luego -en esta idea nos formamos- cuando esté debidamente cimentada por la teoría. Pero luego al dar de bruces con la profesión, es cuando vemos que, o no nacimos o no nos educaron para ella $[\ldots]^{39}$.

Como colofón a su ensayo, Ferrant apunta que lo verdaderamente importante es la educación de carácter general más que la preparación especializada, puesto que, a su juicio, cuando el trabajo profesional se ve desatendido por la opinión de los no profesionales, el esfuerzo, la obra de aquéllos, es destruida por éstos ${ }^{40}$.

Después de casi seis meses de permanencia en Barcelona, no sin grandes dificultades, el 20 de mayo de 1938, el Subsecretario del Ministerio de Instrucción Pública y Sanidad, J. Puig Elías, autorizó a Ferrant a reintegrarse a su cátedra de modelado en Madrid, según consta en un comunicado redactado a su nombre:

"Una vez cumplida la misión que en esta capital le fue encomendada por la Dirección General de Bellas Artes, al profesor de la Escuela de Artes y Oficios Artísticos de Madrid, D. Ángel Ferrant, se le autoriza a que pueda reintegrarse a su cargo en dicha capital, rogando a las autoridades correspondientes que se le faciliten los medios de transporte necesarios"41.

38 Ibidem, p. 25.

39 Ibidem, pp. 25-26.

40 Ibidem, p. 26.

41 Véase "Comunicado en el que se autoriza la reincorporación de Ferrant a su cargo". [Expediente personal de Ángel Ferrant. (Leg. 5). IPHE, Madrid.] 
El plan de Ferrant para reformar la Escuela Superior de Bellas Artes jamás se hizo efectivo. La inminente entrada del ejército nacional en Cataluña, producida el 25 de marzo de 1938, colocó en una difícil situación al gobierno de la República, y en estas circunstancias era imposible llevar a cabo ningún plan de reforma educativa. Así pues, el proyecto de Ferrant entró en el olvido -el régimen franquista tampoco lo tuvo en consideración ${ }^{42}-$. Desaprovecharlo supuso un atraso, inclusive supone. La clarividencia de sus propuestas educativas y la vigencia de algunas rémoras citadas son un testimonio elocuente, máxime cuando hacer realidad el Espacio Europeo de Educación Superior se ha convertido en el gran desafío de nuestro sistema universitario actual.

Fecha de recepción: 22-I-2007

Fecha de aceptación: 12-IX-2007

42 Durante el franquismo, las principales medidas legales concernientes a la enseñanza del arte fueron las Órdenes de junio y agosto de 1939 para reorganizar las Escuelas Superiores de Valencia y Madrid, y el Decreto de 30 de julio de 1940 de reorganización de los estudios. 